\title{
PENGARUH KEJELASAN SASARAN ANGGARAN, PENGENDALIAN AKUNTANSI, PENGENDALIAN MANAJERIAL, DAN SISTEM PELAPORAN TERHADAP AKUNTABILITAS KINERJA PEMERINTAH KABUPATEN BADUNG
}

\author{
I Dewa Ayu Mita Andriani B ${ }^{1}$, I Made Wianto Putra², Ni Putu Riasning 3 \\ Program Studi Akuntnsi \\ Fakultas Ekonomi Universtas Warmadewa, Bali, Indonesia \\ E-mail : i.d.a.mitaandriani.b@gmail.com
}

\begin{abstract}
ABSTRAK
Peneltian bertujuan untuk menguji secara empiris pengaruh masing-masing variabel yaitu Kejelesan Saseran Angaran, Pengendelian Akuntansi, Pengendelian Manajarial, dan System Peleporan terhadap Akuntablitas Kinarja pada Pemerintah Kabupaten Badung. Metode dan jenis data yang digunakan adalah metode kuantitatif. Teknik pengambilan sampel dilakukan dengan teknik purposive sampling. Penelitian ini menggunakan data primer berupa kuesioner yang diukur dengan skala likert 1-5. Responden yang dijadikan sebagai sampel sebanyak 100 responden dari 25 OPD (Organisasi Perangkat Daerah) Kabupaten Badung. Metode analisis data dalam penelitian ini adalah uji asumsi klasik, analisis regresi linear berganda, uji kelayakan model, dan uji hipotesis. Berdasarkan hasil peneltian menunjukan bahwa varibel kejelesan saseran anggeran, pengendalan akuntensi, pengendalan manajarial, dan system peleporan berpengaruh postif dan signifikannifikan terhadap akuntabiltas kinarja pada pemerintah Kabupaten Badung.
\end{abstract}

Kata kunci: Kejelasan Sasaran Anggaran, Pengendalian Akuntansi, Pengendalian Manajerial, Sistem Pelaporan, Akuntabilitas Kinerja.

\begin{abstract}
The research aims to empirically test the effect of each variable, namely Saseran Angaran Clarity, Accounting Control, Manajaral Control, and Reporting System on Kinarja Accountability in the Government of Badung Regency. The method and type of data used are quantitative methods. The sampling technique is done by purposive sampling technique. This study uses primary data in the form of a questionnaire measured with a Likert scale of 1-5. Respondents used as a sample of 100 respondents from 25 Regional Representative Organizations (OPD) of Badung Regency. Data analysis methods in this study are the classic assumption test, multiple linear regression analysis, the model feasibility test, and the hypothesis test. Based on the results of the research, it shows that the variability of budgetary accountability, control of accountability, control of management, and
\end{abstract}


reporting systems have a positive and signifikannificant influence on the performance of the Governments' Performnace in Badung Regency Government.

Keywords: Clarity of Budget Goals, Accounting Control, Managerial Control, Reporting Systems, Performance Accountability.

\section{A. PENDAHLUAN}

Kemajuan suatu negara sangat dipengaruihi oleh peran dan kinarja pemerintah. Pemerintah harus bisa mendukung organisasi penyedia layanan publik agar mengelola aset-aset public sacara ekonamis, efisien, dan efaktif sebagai bentuk pertanggungjawaban terhadap masyarakat. Pemerintah melakukan pertangungjawban lambaga public untuk melakkan pengelolan organsasi sacara ekonomi, efsien, dan efaktif disebut sebagai akuntablitas kinerja pemerintah (Mahmudi, 2018:19). Dalam pelaksanaan akuntabilitas kinerja, organsasi sector pablik berkwajiban untuk memberkan infarmasi sebegai bantuk pamenuhan hak-hak pablik.

Terdapat beberapa penelitian yang meneliti hal serupa yaitu, (Fitri Lestari, 2015), (Made Astari Pradanya Dewi, 2015), (Yunita Sari, 2017), (Yoma Achmad Faizal, 2018), (Riska Dwi Fitriana, 2018), (Khairunsyah, 2018), dan (Devika Diah, 2019). Bardasarkan hesil panelitian yang talah dlakukan oleh 7 paneliti tarsebut mendapatkan hasil yang berbeda-beda sahingga diperlukan pangujian kambali guna mnyumbangkan hasil risat trbaru.

Risat ini bertujuan untk menguji sacara empiris pangaruh 1) kejelasan sasaran anggaran, 2) pengendalian akuntansi, 3) pengendalian manajerial, 4) system pelaponan tehadap akuntablitas kinarja pada organisasi parangkat daerah Kabupaten Badung. Hasl riset ini bermanfaat bagi pemerintah untuk melakukan upaya peningkatan akuntabilitas kinerja kedepannya.

\section{B. TNJAUAN PUSTAKA}

\section{Teori Keagenan \& Good Governance}

Konsep mendeskrpsikan hubngan prinspal (publik/masyarakat) dan agen (pemerintah), prinspal mengontrak agen untk bekarja demi kapentingan atau tujuan prinspal sahingga principal memberkan wewanang pembuatn keputusan 
kepada agen untk mencapai tujuan tersebut disebut sebagai teori keagenan. Good Governance diartikan sebagai teta kelola kapemerintahan yang baik. Good Governance yaitu suatu konsepsi pengelolaan organisasi dalam lingkup luas, melibatkan institusi lain dan peran masyarakat untuk mengontrol organisasi agar transparan, akuntabel,responsive, efisien, efektif, dan berkinerja tinggi (Mahmudi, 2018:28). Dengan kedua teori ini digunakan sebagai teori utama, diharapkan dapat mengurangi Tindakan-tindakan pemerintah yang menyimpng diluar kendali publk.

2. Kejelasan Sasaran Anggaran

Istrumen parencanaan dan pangendalian manajamen yang memiliki perang utama dalam organissi sector public adalah anggaran. Sifat partispatif yang melbatkan masyarkat dalam parencanaan angaran agar asprasi dan kabutuhan publik dapat diakomdasi merupakan sifat penting dari anggaran sektor publik (Mahmudi, 2018:59). Dengan semakin jelas sasaran anggaran dapat digunakan untuk memantaw tingkat pencapaian kinerja organisasi (realisasi) dengan target berupa angganan yang ditetapkan selama periode tertentu (Mahmudi, 2018:64).

3. Pengendalian Akuntansi

Pengendalian yaitu kebijakan dan prosedur yang diterapkan organisasi untuk memastikan telah dilakukan pemantauan yang memadai serta respon risiko telah dilakukan secara efektif (Mahmudi, 2018:264). Dalam mamberikan padoman panyusunan leporan kauangan yang mamenuhi karakterstik kualtatif laporan kauangan yang baik adalah hal yang terpenting dalam sebuah pengendalian akuntansi.

\section{Pengendalian Manajerial}

Proses pangendalian yang melekat pada tindakan dan kegiatan pimpnan organisasi berserta seluruh pegawe yang dilakukan bkn hanya bersifat incidental dan responsive atas kasus tertentu saja tp bersifat terus-menerus disebut sebagai pengendalian manajerial (Mahmudi, 2018:252). Kegiatan pengendalian membantu memastikan bahwa arahan pimpinan organisasi pemerintah telah dilaksanakan. Dengan sitem pengendalin manajeril yang baik maka berbaga penyimpangan, kcurangan, korups, dan kesalahan dapat diminimalisasi sehingga asset-aset organisas dapat terlindungi. 


\section{Sistem Pelaporan}

Instrumen panting bagi pamerintah untk manunjukan transparansi dan akuntabilitas adalah laporan keuangan (Mahmudi, 2018:15). Dalam memberikan informasi keuangan sabagai pertimbangan pembuatan kaputusan dan untuk pangukuran dan evaluasi kinarja diperlukannya sistem pelaporan. System pelaporan diperlukan untuk mengukur aktivitas-aktivitas yang dilaksanakan dalam menngkatkn akuntablitas kinrja pda pelaksanan suatu rencna/wakut mengmplementasikan suatu angaran, sehingga pihak-pihak yang berkepentingan dapat mengetahui hasil dari pelaksanaan rencana/pencapain angaran yang ditetapkan.

6. Akuntabilitas Kinerja

Kewajiban suatu organisasi pemerintah untuk mempertanggungjawabkan keberhasilan dan kegagalan misi organisas dalam mencapai sasaran dan tujuan yang telah ditetapkan melalu sistem pertanggungjwban secara periodic melalui media berupa laporn akuntablitas kinerja pemerinth.

\section{METODE PENELITIAN}

Penelitian ini dilaksanakan pada Organisasi Perangkat Daerah (OPD) Kabupaten Badung yang beralamat Jl. Raya Sempidi, Mengwi, Badung, Bali. Penelitian ini menggunakan populasi sebanyak 25 Organisasi Perangkat Daerah (OPD) dengan purposive sampling merupakan motode yang digunakan sebagai penentuan sampel dengan pertimbangan tertentu.

Data kuantitatif merupakan jeniis data yang dgunakan pada peneltian ini. Data yang berbentuk kata, kalimat, narasi, gerak tubuh, ekspresi wajah, bagan, gambar dan foto disebut sebagai data kuantitatif (Sugiyono, 2019:9). Data tsb ddapatkan dari jmlh nila yang dhasilkan dari kuisioner yang telah dsebarkan.

Dalam pengumpulan data untuk penelitian ini digunakan metode pengumpulan data dengan penyebaran kuisioner. Teknik pengumpulan data yang dlakukan dengan cara mmberi pernyatan trtulis kepada respondan untuk djawabnya atau disebut dengan Kuisioner (Sugiyono 2019:199).

Teknik analiss data dalam peneltian ini dilakukan dengan bberapa uji antra 
laiin: uji statistik deskriptif, uji intrumen yang terdiri atas uji validtas dan uji reliabiltas, uji asumsi klasik yang terdri atas uji normalitas, uji multikolineartas dan uji heterokedstistas, dan uji hipotsis yaitu analsis regresi lnier brganda, uji F, dan uji t.

\section{HASIL DAN PEMBAHASAN}

Responden pada penelitian ini berjumlah 100 orang. Karakteristik responden pada penelitian ini terdiri dari jenis kelamin, jabatan, tingkat Pendidikan, dan lama bekerja. Berdasarkan jenis kelamin, responden laki-laki berjumlah 54 orang atau sebesar 54\% dan responden perempuan berjumlah 46 orang atau $46 \%$. Hal ini menunjukan bahwa sebagian besar responden adalah laki-laki. Berdasarkan jabatan terdapat 4 golongan jabatan yaitu Kepala Dinas, Kepala Sub Bagian Keuangan, Kepala Sub Bagian Umum dan Kepegawaian, Kepala Sub Bagian Perencanaan yang masing-masing berjumlah 25 orang atau $25 \%$. Berdasarkan tingkat pendidikan, responden yang bergelar S1 berjumlah 62 orang atau $62 \%$ dan responden yang bergelar S2 berjumlah 38 orang atau 38\%. Hal ini menunjukan bahwa Sebagian besar responden bergelar S1. Berdasarkan lama bekerja, seluruh responden yang digunakan telah bekerja lebih dari 5 tahun.

\section{Pengujiian Instrumen}

Berdasarkan uji validtas dan reliabltas, dperoleh hasl bahwa nilaii dari seluruh variabel lebih besar dari $\mathrm{r}$ tabel sebesar 0,196 sebingga data dinyatakan valids. Sedangkan dari nilei Cronbach's Alpha dimna ke 5 variabel lebih besar dari 0,70 yatu sbesar 0,9 sahingga data dinyatakan reliabels.

\section{Uji Asumsi Klasik}

Berdasarkan hasil uji asumsii klasik dengan uji normalits menunjukan nilai Kolmogorov sbesar 0,757 nilai tsb lbih besr dbandingkn nilai kolmogoriv tabel sbesar 0,05 maka dapat dikatakan data yang dgunakan terdstribusi norml,. Uji multikolinieritas tdk trdapat variabl bebas yang memliki nilai toleran kurang dari 0,10 dan nilai VIF lebih dr 10 maka dari itu model rgres bebas dr gejala multikolinearits. Uji heterokedaststas mennjukn bahwa masng-masng model memliki nilai signifikan. lebih besr 
dari $5 \%(0,05)$ maka varibel bebas yang saya gunakn tidak berpengaruh secara signifikan. terhadap varibel terikatny.

3. Analisis Regresi Linier Berganda

Dari analisis regresi linier berganda didapatkan hasil persamaan regresi $Y=0,323 X_{1}+0,213 X_{2}+0,311 X_{3}+0,237 X_{4}$. Dari persmaan tsb mennjukan bahwa selurh varibel koefisien regresi berpengaruh positif terhadap akuntabilitas kinerja.

\section{Uji Kelayakan Model}

Dari hasil uji kelayakan madel nilai Adjust $R$ Square $\left(\mathrm{R}^{2}\right)=64,5$ persen. Hasil sebesar 64,5 persen mangartikan bahwa akuntabilitas kinerja instansi pemerintah (Y) dipengarhi oleh varibel kejelsan sasaan anggaran(X1), pengendalan akuntansi (X2), pengendalan manajerial (X3) dan system pelaporan (X4) dan sisnya sebesar 35,5 persen dipengarhi oleh varibel lain dluar penelitan ini.

5. Uji Signifikannifikansi (F-test)

Berdasarkan (Uji F-test) mengasilkan nilai F sebesar 46,052 serta signifikannifkan 0,000 < 0,05. Dari hasil tsb dapt dikatakan bahwa hubngan kejlasan sasran anggaran, pengendalan akuntans, pengendalan manajeral dan system pelaporan berpengaruh signifikannifikan terhadp akuntabiltas kinerja pd pemerintah Kabupaten Badung.

\section{Uji Hipotesis}

Berdasarkan hasil uji hipotesis menghasilkan nilai koefsien ragresi kejelesan sasaran anggaran sbesar 0,323 dan nilai signifikannifkansi 0.000 $<0.05$, membuktkn bahwa kejelesan saseran anggaran berpengaruh positif signifikannfikan terhadp akuntabiltas kineja pd pemerintah Kabupaten Badung, yang artinya $\mathrm{H}_{\mathrm{o}}$ ditolak dan $\mathrm{H}_{\mathrm{I}}$ diterima.

Nilai koefsien regresi pada varibel Pengendalian Akuntansi sebesar 0,213 dan nilai signifikannifkansi $0.003<0.05$, membuktikan bahwa pengendalian akuntansi berpengaruh postif signifikannfikan terhadap akuntabilitas knerja pemerintah Kabupaten Badung, yang artinya $\mathrm{H}_{\mathrm{o}}$ dtolak dan $\mathrm{H}_{2}$ dterima.

Nilai koefisien regresi pada variabel Pengendalian Manajerial sebesar 0,311 dan nilai signifikannifkansi $0.000<0.05$, membuktikan bahwa 
pengendalian manajerial berpengaruh positif signifikannfikan trhadap akuntablitas knerja pada pemerintah Kabupaten Badung, yang artinya $\mathrm{H}_{\mathrm{o}}$ dtolak dan $\mathrm{H}_{3}$ diterima.

Nilai koefisien regresi pada variable system pelaporan sbesar 0,237 dan nilai signifikannifkansi $0.002<0.05$, membuktikan bahwa sistem pelaporn berpengaruh postif signifikannfikan trhadap akuntabilitas knerja pada pemerintah Kabupaten Badung, yang artinya $\mathrm{H}_{\mathrm{o}}$ dtolak dan $\mathrm{H}_{4}$ dterima.

\section{E. PENUTUP}

Dari hasil analsis data dan pembhasan dalam peneltian ini ddapat simpulan bahwa variabel Kejelsan Saseran Anggeran, Pengandelian Akuntensi, Pengendelian Manajarial, dan Sistem Peleporan secara parsial berpengaruh postif signifikannifkan terhadap akuntablitas kinerja pada pemerintah daerah Kabupaten Badung. Dengen semakin baik kejelesan saseran anggeran, pengendalan akuntansi, pengendlian manajarial, dan system peleporan maka akan meningkankan akuntablitas kinerja pada pemerintah Kabupaten Badung. Dari penalitian yang telah dlakukan dtt dtemukan kekurangan, oleh karena itu untuk peneliti selanjutnya diharapkan untuk menmbahkan varibel-varibel lainya yang brhubungan dengan hal-hal yang memungknkan berpengaruh terhadp akuntabilitas knerja pemerintah seperti kompetensi aparatur, transparansi publik, dan aktivitas.

\section{DAFTAR PUSTAKA}

Khairunsyah. (2018). Pengaruh Kejelasan Sasaran Anggaran, Sistem Pelaporan, Kompetensi Terhadap Akuntabilitas Kinerja Instansi Pemerintah Dimediasi Oleh Komitmen Organisasi. Vol. X. No. 1. Januari 2018 Jurnal Tepak Manajemen Bisnis.

Mahmudi. (2018). Akuntansi Sektor Publik. Yogyakarta: UII Press.

Mahsun, Mohamad. 2016. Pengukuran Kinerja Sektor Publik. Yogyakarta: BPFEYOGYAKARTA.

Mardiasmo. (2018). Akuntansi Sektor Publik. Yogyakarta: Andi.

Precelina, Devika Diah. 2019. Pengaruh Kejelasan Sasaran Anggaran, 
Pengendalian Akuntansi, dan Sistem Pelaporan Terhadap Akuntabilitas Kinerja Instansi Pemerintah Kabupaten Jombang. E-Jurnal Universitas Negeri Surabaya.

Sugiyono. (2019). Metodelogi Penelotian Bisnis. Bandung: Alfabet 